\title{
Influence of wire arc additive manufacturing of Ti-6Al-4V on microstructure and mechanical properties for potential large-scale aviation parts
}

\author{
D. Elitzer ${ }^{1}$, H.W. Höppel ${ }^{1}$, M. Göken ${ }^{1}$, D. Baier ${ }^{2}$, C. Fuchs ${ }^{2}$, H. Bähr ${ }^{3}$, T. Meyer ${ }^{4}$, A. Gallasch ${ }^{5}$
}

\footnotetext{
${ }^{1}$ Materials Science \& Engineering I, Friedrich-Alexander University Erlangen-Nürnberg

2 Institute for Machine Tools and Industrial Management, Technical University Munich

${ }^{3}$ Aircraft Philipp GmbH \& CO. KG

${ }^{4}$ HEGGEMANN AG

${ }^{5}$ Software Factory GmbH
}

\section{$\underline{\text { Abstract }}$}

As one of the most common Titanium alloys, Ti-6Al-4V faces new challenges concerning the ecological footprint. Due to the current processes, a high metal chip pollution leads to a Buy-to-Fly of 25:1.

In this study the parameter / microstructure relationship of Ti-64 on the mechanical properties are discussed. Wire Arc Additive Manufacturing (WAAM) was applied to build samples for microstructural analyses and compression tests. A stress relief (SR) and a solution treatment and annealing (STA) was performed. It was found that SR had no influence on multi-layered samples due to intrinsic heat-treatment. A STA heat-treatment led to a reduction in the mechanical strength. Helium as process gas resulted in an increased mechanical strength due to higher heat capacity compared to argon.

\section{Introduction}

TiAl6V4 (Ti-64) is one of the most commonly used alloys in the aerospace industry. Nowadays, structural parts are milled from solid blocks, which results in high metal chip pollution and leads to a Buy-to-Fly ratio of 25:1. Thus, the aero industry is on the one hand in need to improve the ecological footprint and on the other hand to lower costs for structural parts [1]. This becomes even more important as the market demand is steadily increasing. A promising possibility for a resource efficient production is Wire Arc Additive Manufacturing (WAAM). It bases on a welding process, is therefore well known for several decades and also established in nearly every industrial sector [2-4]. With this technique, it is feasible to decrease the lead-time, save energy and reduce the material loss, i.e. creating a buy-to-fly ratio of 3:1 [5,6].

By using a wire-arc based way of generative production, it is possible, unlike SLM or EBM processes, to produce at significantly higher application rates and in higher volumes. Another advantage of this near-net-shape production technology lies in the saving of various further processing steps during milling, like roughing.

In Figure 1, the complete process chain of an additively manufactured aviation part is displayed.

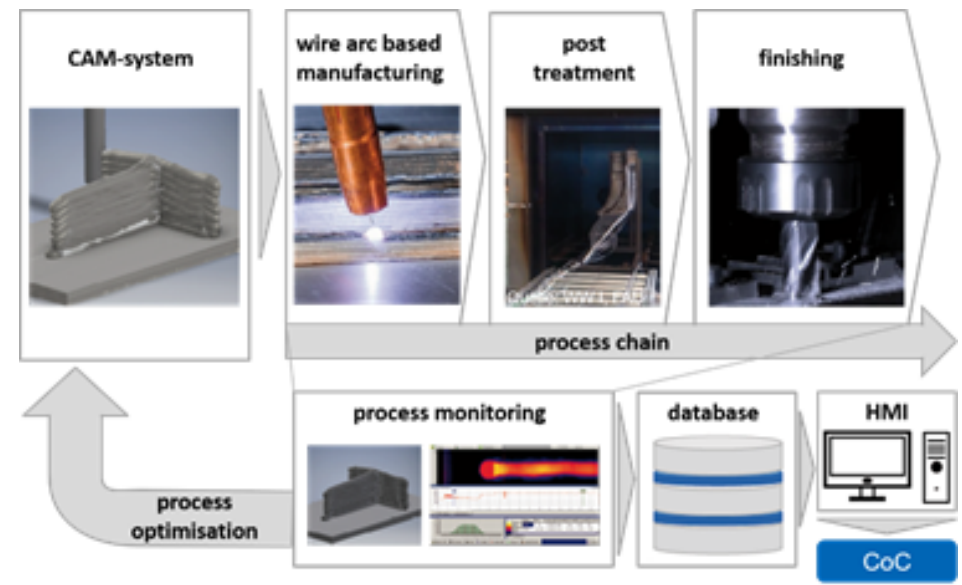

Figure 1: Process chain of the Wire Arc Additive Manufacturing of aviation parts.

(C) The Authors, published by EDP Sciences. This is an open access article distributed under the terms of the Creative Commons Attribution License 4.0 (http://creativecommons.org/licenses/by/4.0/). 
Starting with the CAM-system the digital process chain ensures a seamless transition between each manufacturing step. In order to fulfil the high requirements for the aerospace industry, it is necessary to investigate and to understand in detail how the microstructure is affected by the WAAM-parameters. The type and direction of shield gas flow has to be encountered. Besides the welding parameters, also the post-AM heat treatment is of great importance to achieve an aerospace certified process.

\section{Material and experiments}

Therefore, test samples using Fronius' Cold Metal Transfer Technology (CMT) were produced via a manipulator (BJ1) and a Gefertec arc 605 (GT). Process parameters for BJ1 are displayed in Table 1, however, unfortunately no data were available for the GT samples.

Table1: Process parameters of the samples from the first build job.

\begin{tabular}{|c|c|c|c|c|}
\hline & & \multicolumn{2}{|c|}{ Correction factors } \\
\hline Name & $\mathrm{V}_{\text {weld }}$ & $\mathrm{V}_{\text {wFs }}$ & Arc & Dynamic \\
\hline BJ1-8 & 130 & 4 & 0 & 0 \\
\hline BJ1-9 & 200 & 4 & 0 & 0 \\
\hline BJ1-4 & 160 & 4 & -15 & -5 \\
\hline BJ1-14 & 160 & 4 & 15 & 5 \\
\hline
\end{tabular}

Mechanical properties were studied by compression tests. It was performed on an Instron 4505 testing machine according to DIN 50106 in order to produce a target window in which the process creates stable and recurring properties. The obtained results were compared with reference material of an OEM supplier's production. Microstructural analyses using Zeiss 1540Esb Crossbeam and EBSD. Several common known heat treatments for Ti-alloys were applied and are shown in Table 2.

Table 2: Heat treatment parameters.

\begin{tabular}{|c|c|c|}
\hline Name & Time $/ \mathrm{h}$ & Temperature $/{ }^{\circ} \mathrm{C}$ \\
\hline $\begin{array}{c}\text { Stress Relieving } \\
\text { (SR) }\end{array}$ & 4 & 600 \\
\hline $\begin{array}{c}\text { Solution treatment and } \\
\text { annealing } \\
\text { (STA) }\end{array}$ & 2 & 1200 \\
\hline
\end{tabular}

\section{$\underline{\text { Results and discussion }}$}

First, single -pass experiments were used to determine influence of process parameters on the seam geometry. The results are shown in Figure 2. 


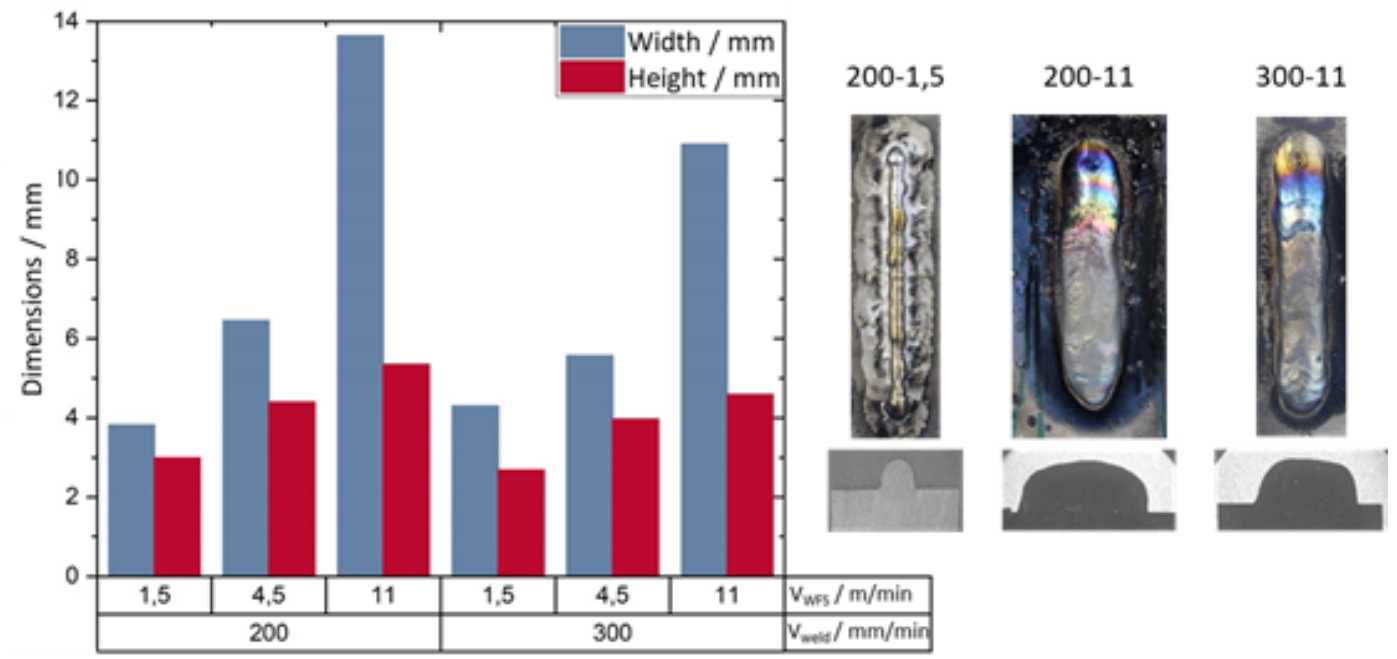

Figure 2: Influence of process parameters on seam geometry

The dimensions of the seam are plotted over the parameters wire feed speed $(1.5,4.5,11 \mathrm{~mm} / \mathrm{min})$ and the welding speeds of 200 and $300 \mathrm{~mm} / \mathrm{min}$. It can be seen, that, with the same welding speed, the weld seam increases in both directions with increasing wire feed speed. Due to the gravitational field and the surface tension of the melt, the expansion is limited in height, whereas an increase of wire feed speed to $11 \mathrm{~m} / \mathrm{min}$ causes a widened seam by a factor of three. An increase in the welding speed generally has less influence.

Figure 3a) shows a cross-section of a printed wall, $100 \mathrm{~mm}$ in height in the as printed state with a thickness of $10 \mathrm{~mm}$. The macroscopic image clearly shows the weld layers at both edges. It can be seen that in the heat-effected zone (HAZ) the primary grains emerging from the melt during cooling down are reduced due to the increased heat transport into the base plate. The microstructure analyses revealed, that the obtained microstructure strongly changed scale with the height of the wall.

a)

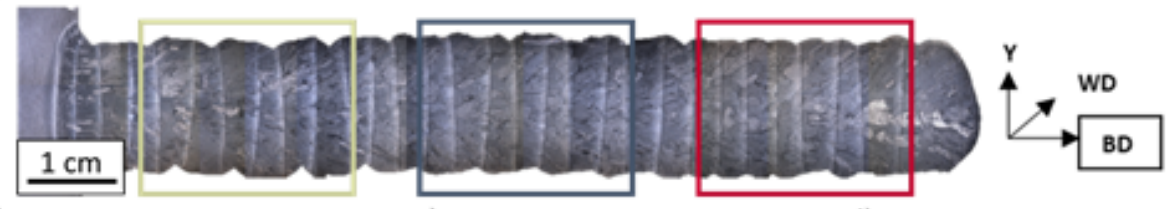

b)

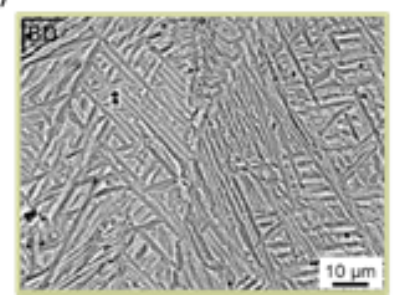

c)

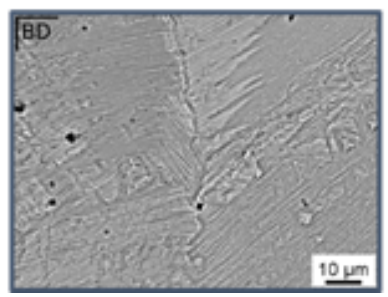

d)

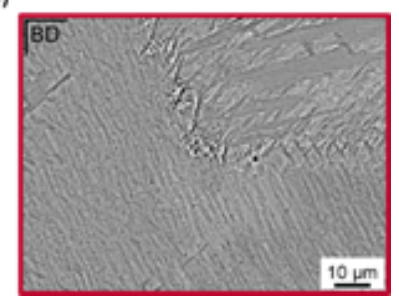

Figure 3: As-Printed state of the deposited wall.

As the layer builds up, the grain size increases and epitaxial growth over several layers occurs as it can be seen in cross-section in Fig. 3 a). It is noticeable that the light lines occur more frequently than layers are present. This suggests that these are linear $\beta$-transus structures, which occur when, due to cyclic heating caused by upcoming layers, the local temperatures reaches more than $985^{\circ} \mathrm{C}$. Thus multi-layer welding, results in an intrinsic heat treatment, which influences the microstructure as a function of the height as considered in Fig. 3 b) - d). It can thus be seen that the lamellae width decreases from bottom to top. Further investigations showed that the microstructure after a stress relieve heat-treatment at $600{ }^{\circ} \mathrm{C}$ for 4 hours does not show any visible change in the optical or scanning electron microscope.

The microstructure of a STA heat-treated sample is shown in Figure 4. 
a)

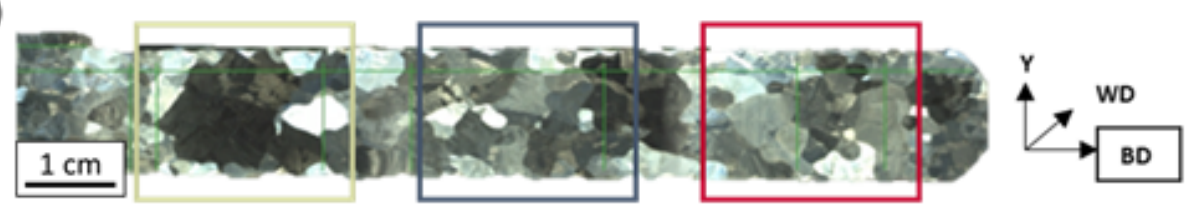

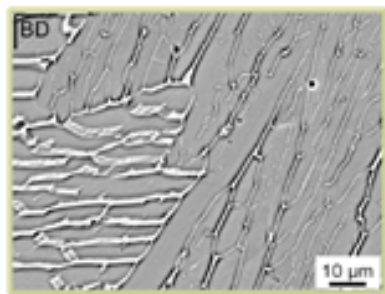

c)

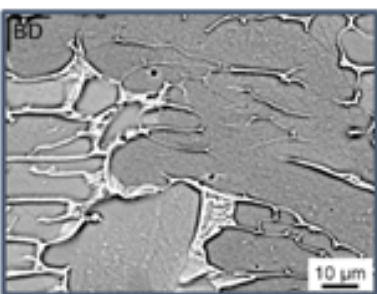

d)

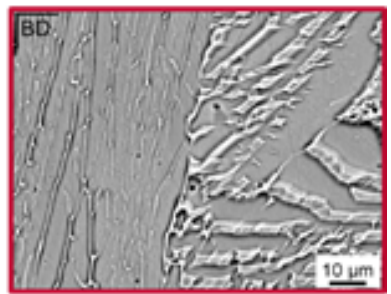

Figure 4: Macro- and microstructure of a STA-Sample.

After solution annealing at $1200^{\circ} \mathrm{C}$ and subsequent aging at $843^{\circ} \mathrm{C}$ both for two hours (STA), the linear $\beta$-transus structure was resolved and the lamellae coarsened significantly. Furthermore, by this heat treatment, inhomogeneity of the microstructure across the specimen disappears and an equiaxed microstructure forms (Fig. 4 b-d).

Mechanical Analyses

As-Printed state specimens (GT-AP) showed similar monotonic strength compared to conventionally manufactured samples in delivery state (ACP-SR) see Fig. 5.

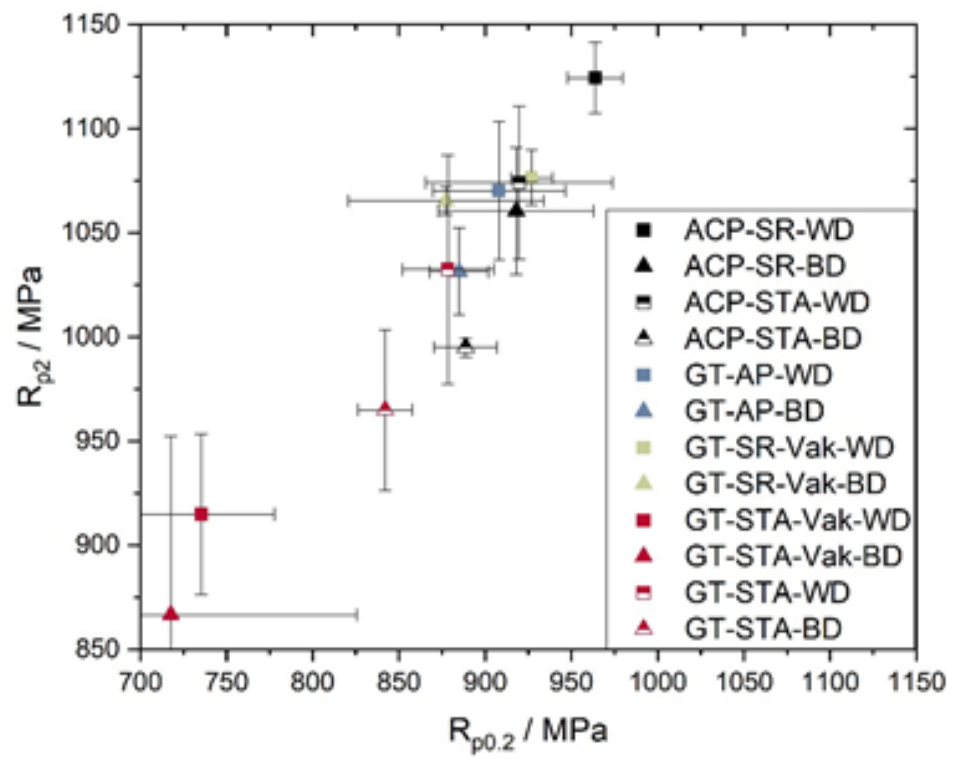

Figure 5: $2 \%$ strength vs. the $0.2 \%$ compression strength of samples (GT) and (ACP). Squares reflect for the rolling / welding direction (WD), triangles for the normal / building direction (BD).

Regardless of the heat treatment, the rolling / welding direction shows an increased strength in all tests compared to normal / building direction. It can be seen that the stress relief annealing of the reference material (GT) achieves similar strengths as the AP state. This can be attributed to the intrinsic heat treatment during the layered construction.

The additive manufacturing process produces strengths of $884 \mathrm{MPa}$ at $0.2 \%$ - compression and $1031 \mathrm{MPa}$ at $2 \%$ compression due to the fine, lamellar structure along the building direction. In the welding direction, the strength values are slightly increased to 908 or, respectively, to $1070 \mathrm{MPa}$, which is due to the process-related texturing. An STA heat treatment leads to a reduction in the mechanical strength of all samples. This can be attributed to the coarsening of the lamellae.

Figure 6 summarizes the results of the first build job in the welding direction and compares them with the results of the reference material. Process parameters are shown in Table 1. The full symbols represent the AP and half the STA states. The wire feed speed ( $\mathrm{V}_{\mathrm{WFS}}$ ) was kept constant at $4 \mathrm{~m} / \mathrm{min}$. 


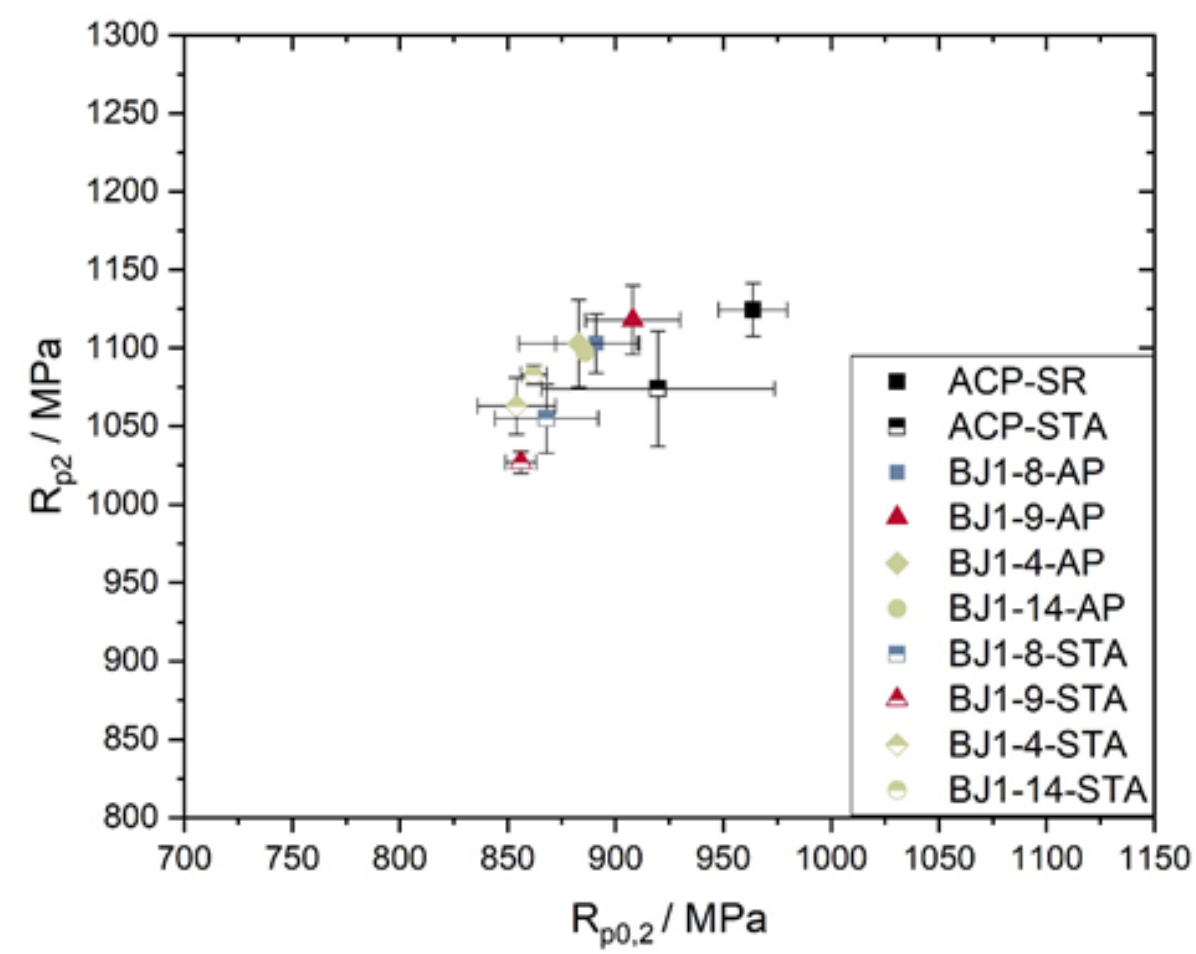

Figure 6: Results of the compression tests of the first build job with argon as process gas in rolling / welding direction.

At a welding speed of $133 \mathrm{~mm} / \mathrm{min}$ (BJ1-8), WAAM Ti-64 reaches a yield strength of $891 \mathrm{MPa}$ and a 2\%-compression strength of $1103 \mathrm{MPa}$. An increase of the welding speed (BJ1-9) causes a slight increase to 908 or, respectively to $1118 \mathrm{MPa}$. This is due to the accelerated cooling caused by the more narrow seams.

The average welding speed of $160 \mathrm{~mm} / \mathrm{min}$ shows similar strengths regardless of the correction factors. A STA heat treatment results in lower strengths for all specimen. The largest weakening occurs for specimen processed at the highest welding speed. After STA, all samples reach a yield strength of about $860 \mathrm{MPa}$.

The comparison with the reference material shows that the strength has already been achieved in single-layer welding tests. In order to check the influence of the process gas on the mechanical properties, a second build job with Helium as process gas was produced. Samples from comparable parameter sets were taken with a welding speed of 200, respectively $300 \mathrm{~mm} / \mathrm{min}$ and a wire feed speed of 4,5 and $11 \mathrm{~m} / \mathrm{min}$ in welding direction. The results are shown in Figure 7.

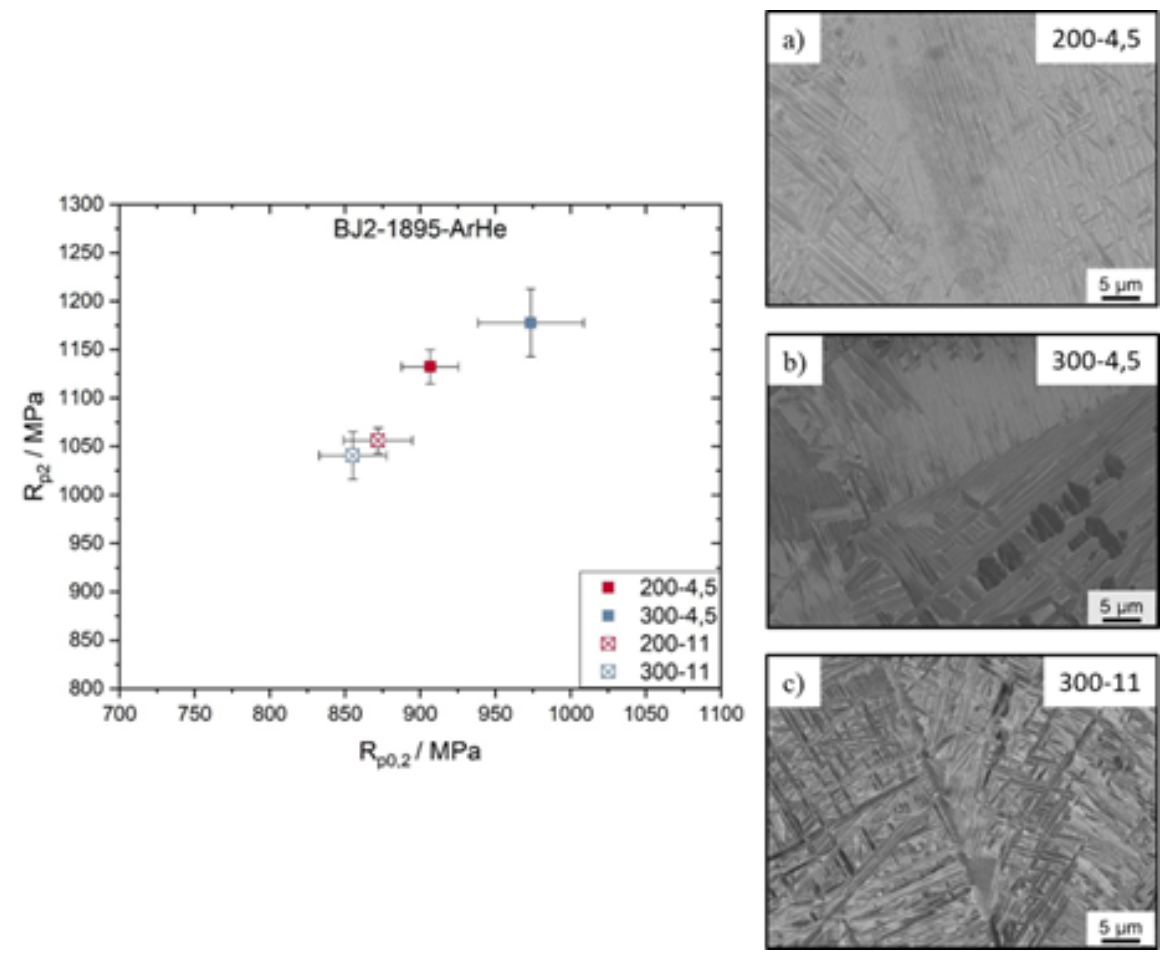

Figure 7: Results of the compression tests of the second build job with Helium as process gas.

It can be seen, that at the same wire feed speed, an increase in the welding speed results again in an increased strength. Considering the bead geometries, this is also due to the faster cooling of the narrower seam. As Fig. 7 c) shows, the increase of wire feed speed causes a coarsening of the lamellae and thus produces lower strengths. It can also be stated that the higher heat capacity of helium used as process gas causes a faster cooling than argon-gas, whereby the strength of 1118 MPa (Argon / Fig. 6, BJ1-9-AP) 
increases to $1132 \mathrm{MPa}$ (Helium) despite a slightly increased wire feed rate. In general, it can be stated that helium as a protective gas produces finer lamellar structures due to the faster cooling. This slightly increases the strength of Ti-64.

\section{Conclusions}

These first results confirm that with a well-chosen process window WAAM achieves mechanical properties that are very close to the required values of conventionally produced Ti-64 specimen. Wire feed speed had a bigger impact on the seam geometry than the welding speed. Epitaxial growth of primary $\beta$-grains over several layers and a graded microstructure in the as-printed state was observed. Due to the rapid cooling strengths of $884 \mathrm{MPa}$ at $0.2 \%$ - compression and $1031 \mathrm{MPa}$ at $2 \%$ compression were achieved during compression tests. A STA heat-treatment led to a reduction in the mechanical strength, which was attributed to a coarsened microstructural change to a fully equiaxed microstructure.

Helium as a process gas increased the quasistatic mechanical strength during compression.

It can be finally stated, that a Wire Arc Additive Manufacturing process is therefore a very promising way for producing high quality titanium parts. However, further dynamic tests must be performed.

\section{$\underline{\text { Acknowledgement }}$}

The research project REGULUS is funded by the Federal Ministry for Economic Affairs and Energy (BMWi) (grant number 20W1709D), supervised by the German Aerospace Center e. V. and developed by five project partners. The authors would like to thank the BMWi as well as the DLR for their support.

\section{References}

[1] E. Brandl, B. Baufeld, C. Leyens, R. Gault, Physics Procedia 5 (2010) 595-606.

[2] DIN-Normenausschuss Schweißen und verwandte Verfahren (NAS), Welding and allied processes, (1973).

[3] R. Acheson, Automatic Welding Apparatus for Weld Build-up and Method of Achieving Weld Build-Up, US4952769A, 1990.

[4] G. Schulze, Die Metallurgie des Schweißens: Eisenwerkstoffe - nichteisenmetallische Werkstoffe, 4., neu bearb. Aufl, Springer, Berlin, 2010.

[5] P.A. Colegrove, H.E. Coules, J. Fairman, F. Martina, T. Kashoob, H. Mamash, L.D. Cozzolino, Journal of Materials Processing Technology 213 (2013) $1782-1791$.

[6] J. Mehnen, J. Ding, H. Lockett, P. Kazanas, in: Global Product Development, Springer, Berlin, Heidelberg, 2011, pp. 721-727. 